\title{
Late Onset Tay-Sachs Disease Presenting as a Brief Psychotic Disorder with Catatonia: A Case Report and Review of the Literature
}

Osama Saleh M.D.

St. Francis Medical Center, Pittsburgh, PA

Follow this and additional works at: https://jdc.jefferson.edu/jeffjpsychiatry

Part of the Psychiatry Commons

Let us know how access to this document benefits you

\section{Recommended Citation}

Saleh, Osama M.D. (2000) "Late Onset Tay-Sachs Disease Presenting as a Brief Psychotic Disorder with Catatonia: A Case Report and Review of the Literature," Jefferson Journal of Psychiatry. Vol. 15 : Iss. 1 , Article 4.

DOI: https://doi.org/10.29046/JJP.015.1.006

Available at: https://jdc.jefferson.edu/jeffjpsychiatry/vol15/iss1/4

This Article is brought to you for free and open access by the Jefferson Digital Commons. The Jefferson Digital Commons is a service of Thomas Jefferson University's Center for Teaching and Learning (CTL). The Commons is a showcase for Jefferson books and journals, peer-reviewed scholarly publications, unique historical collections from the University archives, and teaching tools. The Jefferson Digital Commons allows researchers and interested readers anywhere in the world to learn about and keep up to date with Jefferson scholarship. This article has been accepted for inclusion in Jefferson Journal of Psychiatry by an authorized administrator of the Jefferson Digital Commons. For more information, please contact: JeffersonDigitalCommons@jefferson.edu. 


\title{
Late Onset Tay-Sachs Disease Presenting as a Brief Psychotic Disorder with Catatonia: A Case Report and Review of Literature
}

\author{
Osama Saleh, M.D.
}

\begin{abstract}
This is a case report of late onset Tay-Sachs disease diagnosed in a 14-year-old male non-Jewish adolescent who presented in a psychotic and catatonic state. The objective is to emphasize that Tay-Sachs disease can present with psychiatric symptoms, with a variety of phenotypes from infancy to adulthood, and can affect individuals other than Ashkenazi Jews. Amphiphilic drugs, including phenothiazine and tricyclic antidepressants, may worsen the course of the illness. Resistant catatonia can respond to an extended trial of high dose lorazepam.
\end{abstract}

\section{CASE REPORT}

The patient is a 14-year-old male of Polish and Irish descent transferred to our facility from another hospital.

\section{Chief Complaint}

Over the past four days, the patient became less verbal, seclusive, with poor appetite and decreased sleep.

\section{History of Present Illness}

The patient arrived via ambulance accompanied by his parents. The parents reported that he had been in his usual state of health and attending school regularly until four days prior to admission when he had been teased at school. When he arrived home, the patient was anxious about returning to school the next day, was rambling and making such bizarre statements as: "I smoked a cigarette, I stole a pillow, someone pulled my pants down" and, "They are out to get me." The patient became less and less verbal, more anxious and fidgety, and his appetite diminished significantly. He became mute, secluding himself in his room.

Dr. Saleh wishes to acknowledge his Program Director, David J. Lynn, M.D. for his help and encouragement in preparing this manuscript. 
Past Psychiatric History

The patient had never had a similar episode, and there was no past psychiatric history.

\section{Developmental and Medical History}

The parents reported the that patient's birth was without complications and early milestones were met except for speech. The patient's speech reportedly had always been difficult to understand.

The patient was diagnosed with a primary speech impediment. He received speech therapy at age 4 with some improvement. By age 5 , the parents observed that the patient appeared thinner and weaker than his peers and could not keep up with other children. Neurological evaluation at this time revealed dysarthria, low muscle mass with increased tone, abnormal wide based gait, and abnormally brisk bilateral deep tendon reflexes. The patient had CT scan and MRI, both unrevealing; second MRI the following year was again unrevealing. The possibilities entertained at the time included leukodystrophy or a brain stem lesion, but there was no clear evidence for either. The patient was enrolled in a program of physical and occupational therapy, but there was no improvement of his neurological symptoms.

Between the ages of 11 and 13, the patient gradually developed difficulty with chewing and swallowing and had some drooling. The parents reported that he would clench his teeth when he spoke, giving his speech an even poorer quality. At that time the patient had an MRI which showed mild cerebellar degeneration. Metabolic studies including long chain fatty acids, plasma amino acids, creatinine phosphokinase, pyruvate, ammonia and lactate which were all within normal limits.

\section{Social History}

The patient resides with his parents. The family is described as close knit and supportive. They describe him as gentle and shy. He has never had many friends. He enjoys watching sports on TV and playing Nintendo but he engages in little outdoor activity. $\mathrm{He}$ is in the 8th grade of regular classes and has been maintaining grades, of A's, B's, and C's. He had to repeat second grade due to difficulty with reading and writing.

\section{Family History}

The family history is unremarkable except that the patient's father had a childhood speech impediment which later resolved. The patient is the youngest of four children. His siblings have had unremarkable medical histories.

\section{Mental Status Examination}

14-year-old white male presented to us as thin, apprehensive and immobile. He sat in his chair with glassy eyes. He didn't answer any questions, didn't move, didn't even nod his head. He didn't follow any commands. Waxy flexibility could be elicited. 


\section{Hospital Course}

Upon admission to the unit, the patient was accompanied by his parents. He did not show any emotion when they departed. He sat mute on his bed. The patient was started on lorazepam $0.5 \mathrm{mg}$ three times a day. He resisted taking the medication. $\mathrm{He}$ ate minimally and continued to be withdrawn and mute. He did not follow commands. Every attempt to administer medication was met with resistance. Communication with the patient was attempted in writing but his answers were vague or inappropriate. At midnight the day of admission, the patient was found naked in the middle of his room, confused and unable to sleep until 3:00 a.m. On the second day after admission, the patient continued to be mostly mute, answering some questions with only a single word. By the third day, the patient took medication without resistance. He was reported to have trouble swallowing. He was continued on lorazepam $0.5 \mathrm{mg}$ three times a day and started on risperidone $0.5 \mathrm{mg}$ twice a day. He started to improve and showed some understanding of conversation and commands by nodding his head. He became cooperative and appeared less frightened. His appetite improved and he began to participate in group activities by playing ping pong. $\mathrm{He}$ attended school classes in the partial hospital program, followed teachers' directions and played flag football. His speech continued to be dysarthric. He also continued to display facial grimacing. His gait remained wide-based. The patient's difficulty in swallowing, however, had improved by this time.

In his discussion of the events precipitating the admission, he was vague. He could articulate very little about what had led up to this point or his subjective experience while acutely psychotic. When school difficulties were directly explored, the patient did say that a bad day at school had preceded his decline in functioning. He described being called names by peers, who taunted him, stole his books and attempted to remove his pants. He recalled that he later became confused but could not say what he was thinking or feeling. He described no hallucinations or delusions during this time. He said he had stopped eating, but he could not say why. He commented that the hospital felt like a safe place to be when he felt confused. He did say that his brother's upcoming marriage and departure from the home were affecting him, but he could not describe how. At this time, a diagnosis of brief psychotic disorder was reached. It was felt that a follow-up evaluation would be needed to reach a definitive diagnosis. The patient was discharged to home and home schooling was ordered. Discharge medications included risperidone $0.5 \mathrm{mg}$ twice a day and lorazepam $0.5 \mathrm{mg}$ three times a day.

According to his mother, the patient was compliant with his medications and doing well on the first day post-discharge. On the second day, the patient experienced a sore throat with low-grade fever, refused his medications, once again eating and speaking less. By the fourth day he had again become mute and was not eating well. His parents brought him back to the hospital. He was once again mute and catatonic with waxy flexibility. He refused to take medication or to eat. He was started on intramuscular lorazepam $0.5 \mathrm{mg} \mathrm{q} 6 \mathrm{~h}$, and haloperidol $1 \mathrm{mg}$ twice a day. After 4-5 hours, the patient had fever of $101^{\circ} \mathrm{F}$. Neuroleptic malignant syndrome was considered. Neuroleptics were discontinued; lorazepam $0.5 \mathrm{mg}$ every six hours intramuscu- 
lar was maintained. An internal medicine consultation was requested. A chest X-ray raised the possibility of left lower lobe pneumonia. Intravenous normal saline was started as the patient was dehydrated. The patient began to show slow improvement and began to drink and eat. Lorazepam $1 \mathrm{mg}$ every six hours and risperidone $1 \mathrm{mg}$ at bed time and $0.5 \mathrm{mg}$ every morning by mouth were started as neuroleptic syndrome was ruled out as CPK done at the time was WNL. The patient started to talk about feeling depressed and expressed suicidal ideation. Fluoxetine hydrochloride $20 \mathrm{mg}$ po daily was started. The patient seemed over-sedated, as he would sleep on his desk at the hospital school. His lorazepam and risperidone were both decreased to $1 \mathrm{mg}$ qhs. When the patient went without lorazepam for a period of 15 hours, he began to quickly deteriorate, becoming mute and catatonic. Intramuscular lorazepam $1 \mathrm{mg}$ q6h was resumed and the patient slowly improved. The onset of psychosis and catatonia in this patient with neurological symptoms and signs such as dysarthria, abnormal gait, hypertonia, and hyper-reflexia, were strongly suggestive of a metabolic disorder. In reviewing the previous metabolic tests, it was noted that lysosomal enzymes (specifically hexosaminidase A) were not tested. The suspicion of late onset Tay-Sachs disease was confirmed by laboratory analysis on the serum. Although tests revealed total hexosaminidase (A \& B) to be within the normal range, hexosaminidase A was only $1 \%$ of the total (normal $56 \%-80 \%$ ). In the leukocytes, hexosaminidase A was only $7 \%$ of the total (normal $63 \%-75 \%$ ).

Considering the positive serum and leucocyte findings for hexosaminidase A deficiency, we reviewed the literature for treatment of psychosis and catatonia associated with late onset Tay-Sachs disease. The literature suggested withholding all antipsychotics and increasing lorazepam, which was increased to $1 \mathrm{mg}$ four times a day; fluoxetine hydrochloride $20 \mathrm{mg}$ daily was continued. The patient improved quickly. His movements were more spontaneous, his eating improved and he became more verbal and interactive with peers. His parents felt that he had returned to his usual state of health. The patient was discharged home with a plan for him to follow-up with a partial hospitalization program. He was to continue the lorazepam at $1 \mathrm{mg}$ q6h, fluoxetine hydrochloride at $20 \mathrm{mg}$ daily. He was also to get pediatric follow-up at the referring hospital.

\section{DISCUSSION AND REVIEW OF LATE ONSET TAY-SACHS DISEASE INTRODUCTION}

Disorders of ganglioside breakdown can have serious clinical consequences. For example, the genetic deficiency of hex-A activity causes intralysosomal accumulation of the ganglioside $\mathrm{GM}_{2}$ which results in destruction of the neuron. This is the pathogenesis of the neuronal breakdown that leads to the expression of symptoms in Tay-Sachs disease. $\mathrm{GM}_{2}$ gangliosidoses have been subclassified clinically according to the age of onset of symptoms into infantile, juvenile, and adult forms. However, differentiating between juvenile and adult variants of the disease is often difficult, as many patients presenting in adulthood report symptoms dating back to early childhood. In the infantile form $(1,2)$ afflicted children, although normal at birth, develop 
hypotonia and psychomotor retardation in the first year of life. The central nervous system degeneration proceeds rapidly, and spasticity and blindness soon follow. The classical "cherry-red macula," first described with Tay-Sachs disease and now known to be present in many storage diseases, is a normal segment of the retina rendered vivid by contiguous white areas that contain the stored material (3). Respiratory problems are common and pneumonia is the usual cause of death by 3 years of age (3).

The juvenile onset $(1,4,5)$ of Tay-Sachs disease (also called late infantile form) has its onset ranging from 1 to 9 years. Early milestones are often normally achieved, but are followed by a development of prominent neurological deficits. These deficits include seizures, choreiform and dystonic movements, incontinence, dysphagia, gait disturbance, immobility and dementia. Death usually occurs by age 15 years. When one can date signs and symptoms to childhood, the more benign course of illness leads to it being classified as adult onset. The adult onset variant $(1,4)$ (also called chronic or late onset Tay-Sachs Disease), usually presents after age 10 years. However, symptoms can be discerned in retrospect as early as the first or second year of life. More than $80 \%$ of the patients describe having mild neurological symptoms before the age of 20 years (4). Commonly, the presenting symptoms include stuttering, grimacing on speaking, cramps after mild exercise, difficulty climbing stairs or riding a bicycle, or an inability to participate in sports. Patients can be described as clumsy and slow in school. In later stages, patients will have more pronounced neurologic symptoms including ataxic gait, hypotonia, rigidity, dysarthria, or cognitive impairment. Psychiatric symptoms are reported in more than $50 \%$ of cases $(1,4)$. The most common psychiatric symptoms are psychosis with hallucinations or delusions. Catatonia and mood symptoms have also been reported. Patients might be given an initial diagnosis of schizophrenia, bipolar disorder, psychotic depression, or major depression.

\section{GENETICS OF TAY-SACHS DISEASE}

Tay-Sachs disease is caused by a deficiency of hexosaminidase A and is inherited as an autosomal recessive trait. At least fifty-four specific hexosaminidase A mutations have been reported to date. Most mutations are associated with the severe, infantile-onset disease which has a clear predilection for Ashkenazi Jews (6). Hexosaminidases occur mainly in two isoenzymatic forms: Hex-A and Hex-B. Hexosaminidases $\mathrm{A}$ is composed of $(\alpha)$ and $(\beta)$-subunits; Hex-B is composed only of the $(\beta)$-subunits. The $(\alpha)$ and $(\beta)$ subunits are encoded at different genetic $(\alpha)$ and $(\beta)$ loci, respectively. A mutation on chromosome 15 in the $(\alpha)$ chain region may result in a selective deficiency of Hex A and can cause Tay-Sachs disease. A mutation on chromosome 5, which alters the region coding for the beta subunit, will affect both Hex-A and Hex-B; this induces the Sandhoff variant of the disease characterized by neuropsychiatric disturbance as well as visceral organ involvement $(2,4,7,8)$.

The clinical differentiation of chronic variants due to Hex A deficiency (TaySachs disease variants) from those due to combined Hex A and Hex B deficiency 
(Sandhoff disease variants) is generally not possible. However, late-onset disease due to Hex A deficiency is much more common than that due to combined Hex A and Hex B deficiency.

The infantile form of Tay-Sachs is associated with severe mutations on chromosome 15 leading to the formation of non-functioning mRNA and a total absence of the alpha subunit protein. In the juvenile form of the disease, a point mutation causes the formation of functioning mRNA but defective alpha subunit protein. Patients with the adult form of the disease have point mutations at a different site on the gene than that associated with the juvenile form. The variable mutations sites within the gene probably correspond to the different forms of the $\mathrm{GM}_{2}$ gangliosidoses $(2,4,7,8)$.

\section{NEUROLOGICAL FEATURES OF LATE-ONSET TAY-SAGHS DISEASE}

In late onset Tay-Sachs disease, neurological symptoms can progress slowly with an indolent course and variable clinical presentations. The sensory system, along with cranial and peripheral nerves, is usually spared. Neurons are affected but not the myelin nor the muscle, and so demyelinating neuropathy and myopathy have not been seen. The systems commonly affected are: 1) cerebellum, leading to gait disturbance, ataxia, dysarthria, depressed tendon reflexes, hypotonia, and/or intention tremors; 2) upper motor neurons, leading to weakness, spasticity, increased tendon reflexes, extensor plantar response; 3) basal ganglia, leading to abnormal gait, rigidity, resting tremors, dystonia and other extrapyramidal signs in some patients (Slowly progressive dystonia dominates the clinical course of the disease); and 4) lower motor neuron, leading to weakness, wasting, fasciculations, and/or hypotonia $(1,4,9,10)$.

\section{PSYCHIATRIG FEATURES OF LATE-ONSET TAY-SACHS DISEASE}

Psychiatric features have been reported in more than $50 \%$ of patients with late onset Tay-Sachs disease. Psychosis was reported in about 33\% of those patients $(1,4)$. Disorganized (hebephrenic) schizophrenia was most commonly reported and characterized by disorganized thinking, delusions, auditory hallucinations, inappropriate affect and marked deterioration in the level of functioning. Psychotic episodes were recurrent and chronic inpatient care was often needed. In one case report, the patient had delusions, auditory and visual hallucinations of small animals, and child-like behavior. The patient was diagnosed and treated for schizophrenia before he was diagnosed as late onset Tay-Sachs disease (11). Postpartum psychosis has been reported in another case report (12). Psychosis manifested early in the course of illness in some patients, whereas in other patients psychosis appeared after many years of neurological involvement (11).

Mood disorders including mania with or without psychosis, unipolar depression, and atypical manic states have been described (13).

Cognitive decline has been reported in late onset Tay-Sachs disease, the impairment ranged from mild memory deficit to severe cognitive decline $(4,12,15)$. 
Late onset Tay-Sachs disease should be included in the differential diagnosis of early dementia.

\section{DIAGNOSIS OF LATE ONSET TAY-SACHS DISEASE}

In a patient with psychiatric illness and neurologic symptoms or cognitive impairment, metabolic disorders in general should be considered including $\mathrm{GM}_{2}$ gangliosidoses. Early manifestations of late onset Tay-Sachs include stuttering, dysarthria, weakness, and gait disturbances. Clinical suspicion should be followed by determination of hexosaminidase levels from serum, leucocytes or cultured fibroblasts to diagnose late onset Tay-Sachs disease. In the present case, the poor response to treatment and the presence of psychosis, movement disorder, and speech disturbance led us to consider metabolic disorders which could account for this presentation. Electromyography studies are abnormal in $89 \%$ of the patients, but there are no characteristic abnormalities (1).

There is no significant correlation between clinical signs and radiologic changes in late onset Tay-Sachs disease. Normal results can be reported in MRI and CT scans. Cerebellar atrophy, moderate to severe vermian atrophy, and tonsillar abnormalities have commonly been reported (14). Our patient displayed normal MRI and CT scans initially; later MRI showed mild cerebellar atrophy.

\section{TREATMENT ISSUE}

There is no specific treatment for late onset Tay-Sachs disease. Neurological manifestations are managed supportively with the use of orthopedic and rehabilitative measures where indicated (4).

In psychotic patients with late onset Tay-Sachs disease, the use of neuroleptics has been reported to be of limited efficacy $(4,11)$. It has been noted that patients with psychiatric symptoms and late onset Tay-Sachs have a more severe illness course. It may be because amphophilic drugs, including phenothiazines and tricyclic antidepressants, increase lipidosis, and cause depletion of residual cellular Hex-A $(1,4,6,16)$. Individuals with a variety of brain lesions are also more vulnerable to extrapyramidal side effects. Thus, a patient with late onset Tay-Sachs disease might appear more neurologically impaired, if he has been on neuroleptics (because of extrapyramidal side effects) (4). Lithium has been used in postpartum psychosis associated with late onset Tay-Sachs disease with complete resolution of the delusions within eighteen days (12). Lithium, in combination with tranylcypromine or carbamazepine, has been reported to be effective in several cases (4).

Electroconvulsive therapy (ECT) has been reported to be effective in psychotic depression associated with late onset Tay-Sachs disease, with resolution of chronic auditory hallucinations (17). Fluoxetine hydrochloride has been used following electroconvulsive therapy to prevent relapse; long-term benefit is not reported (17). In our patient, during his catatonic state we tried lorazepam $1 \mathrm{mg}$ tid and risperidone $0.5 \mathrm{mg}$ bid. He was continued on this regimen for 3 weeks, with slow improvement. 
After making the diagnosis of late onset Tay-Sachs disease and reviewing the literature on treatment, we stopped the risperidone (because it was not reported to be used before in late onset Tay-Sachs disease). We increased lorazepam to $1 \mathrm{mg}$ four times a day (there was a one case report of good response in the literature) (11). The patient's catatonia improved rapidly, with return to his baseline in two days, raising the possibility that either risperidone was slowing the improvement or the increase in lorazepam was effective, or both. In his third week of hospitalization the patient was started on fluoxetine hydrochloride $20 \mathrm{mg}$ po daily as the patient was complaining of feeling depressed and suicidal. This did help his depression.

The majority of patients with acute catatonia not related to Tay-Sachs disease respond rapidly to treatment with lorazepam with resolution of the catatonic syndrome within a few hours. In our case the improvement was gradual. This would suggest that it may be beneficial to extend the trial or use a higher dose of lorazepam in those patients whose catatonia does not resolve completely after the first few doses of the drug $(18,19)$.

\section{CONCLUSION}

Late onset Tay-Sachs disease can present with a variety of psychiatric symptoms, can affect adolescents as well as adults, and more than one-third of the cases reported were not of known Jewish descent. Although it is a rare disorder (around one hundred cases have been reported in the literature), late onset Tay-Sachs disease should be considered when evaluating any patient with an atypical neuropsychiatric picture, refractory psychiatric symptoms, or dementia in adolescents or young adults.

\section{REFERENCES}

1. Navon R, Argov Z, Frisch A: Hexosaminidase A deficiency in adults. American Journal of Medical Genetics 1986; 24: 179-196.

2. Johnson WG: The clinical spectrum of hexosaminidase deficiency diseases. Neurology 1981; 31: 1453-1456.

3. Menkes JH: Textbook of Childhood Neurology, 5th Edition. Baltimore, MD, Williams and Wilkins 1995.

4. MacQueen GM, Rosebush PI, Mazurek MF: Neuropsychiatric aspects of the adult variant of Tay-Sachs disease. Neurol and Clin Neurosc, in press.

5. O'Neill B, Butler AB, Young E, Falk PM, Bass NH: Adult-onset $\mathrm{GM}_{2}$ gangliosidosis: Seizures, dementia, and normal pressure hydrocephalus associated with glycolipid storage in the brain and arachnoid granulation. Neurology 1978; 28: 1117-1123.

6. Gravel RA, Clarke JTR, Kaback MM, et al: The $\mathrm{GM}_{2}$ gangliosidoses. In: Scriver CR, Beaudet AL, Sly WS, et al, eds. The Metabolic and Molecular Basis of Inherited Disease. 7th ed. New York, NY: McGraw-Hill; 1995; 2839-2882.

7. Navon R, Argov Z, Brand N, Sandbank U: Adult $\mathrm{GM}_{2}$ gangliosidosis in association with Tay-Sachs disease: A new phenotype. Neurology 1981; 31: 1397-1401.

8. Specola N, Vanier MT, Goutieres F, Mikol J, Aicardi J: The juvenile and chronic forms of $\mathrm{GM}_{2}$ gangliosidosis: clinical and enzymatic heterogeneity. Neurology 1990; 40: 145-150. 
9. Wilner JP, Grabowski GA, Gordon RE, Bender AN, Desnick RJ: Chronic $\mathrm{GM}_{2}$ gangliosidosis masquerading as atypical Friedreich ataxia: Clinical, morphologic, and biochemical studies of nine cases. Neurology 1981; 31: 787-798.

10. Parnes S, Karpati G, Carpenter S, Kin NY, Wolfe LS, Suranyi L: Hexosaminidase-A deficiency presenting as atypical juvenile-onset spinal muscular atrophy. Arch Neurol 1985; 42: 1176-1180.

11. Rosebush PI, Macqueen GM, Clarke JTR, Callahan JW, Strasberg PM, Mazurek MF: Late-onset Tay-Sachs disease presenting as catatonic schizophrenia: diagnostic and treatment issues. J Clin Psychiatry 1995; 56(8): 347-353.

12. Lichtenberg et al: Post-partum psychosis in adult $\mathrm{GM}_{2}$ gangliosidosis: A case report. $\mathrm{Br} \mathrm{J}$ Psychiatry 1988; 153: 387-389.

13. Streifler J, Golomb M, Gadoth N: Psychiatric features of adult $\mathrm{GM}_{2}$ gangliosidosis. $\mathrm{Br} \mathrm{J}$ Psychiatry 1989; 155: 410-413.

14. Streifler JY, Gornish M, Hadar H, Gadoth N: Brain imaging in late-onset $\mathrm{GM}_{2}$ gangliosidosis. Neurology 1993; 43: 2055-2058.

15. Coker SB: The diagnosis of childhood neurodegenerative disorders presenting as dementia in adults. Neurology 1991; 41: 794-798.

16. Navon R, Baram D: Depletion of cellular $\beta$-hexosaminidase by imipramine is prevented by dexamethasone; Implications for treating psychotic hexosaminidase-A deficient patients. Biochemical and Biophysical communications. 1987; 148(3): 1098-1103.

17. Ranshaw PF, Stern TA, Welch C, Schouten R, Kolodny EH: Electroconvulsive therapy treatment of depression in a patient with adult $\mathrm{GM}_{2}$ gangliosidosis. Ann Neurol 1992; 31: 342-344.

18. Rosebush PI, Hildebrand AM, Furlong BG, Mazurek MF: Catatonic syndrome in a general psychiatric inpatient population: Frequency, clinical presentation, and response to lorazepam. J Clin Psychiatry 1990; 51: 357-362.

19. Gaind GS, Rosebush PI, Mazurek MF: Lorazepam treatment of acute and chronic catatonia in two mentally retarded brothers. J Clin Psychiatry 1994; 55(1): 20-22. 